\title{
Metformin treatment in diabetes and heart failure: when academic equipoise meets clinical reality
} Dean T Eurich*1, Ross T Tsuyuki ${ }^{2}$, Sumit R Majumdar ${ }^{1,2}$, Finlay A McAlister ${ }^{1,2}$, Richard Lewanczuk ${ }^{2}$, Marcelo C Shibata ${ }^{2}$ and Jeffrey A Johnson ${ }^{1}$

\author{
Address: ${ }^{1}$ School of Public Health, University of Alberta, Edmonton, Alberta, T6G 2G3, Canada and ${ }^{2}$ Faculty of Medicine and Dentistry, University \\ of Alberta, Edmonton, Alberta, T6G 2C7, Canada \\ Email: Dean T Eurich* - deurich@ualberta.ca; Ross T Tsuyuki - ross.tsuyuki@ualberta.ca; Sumit R Majumdar - me2.majumdar@ualberta.ca; \\ Finlay A McAlister - finlay.mcalister@ualberta.ca; Richard Lewanczuk - rlewancz@gpu.srv.ualberta.ca; \\ Marcelo C Shibata - Marcelo.shibata@ualberta.ca; Jeffrey A Johnson - jeff.johnson@ualberta.ca \\ * Corresponding author
}

Published: 9 February 2009

Trials 2009, 10:12 doi:10.1186/1745-6215-10-12
Received: 2 December 2008

Accepted: 9 February 2009

This article is available from: http://www.trialsjournal.com/content/I0/I/I2

(c) 2009 Eurich et al; licensee BioMed Central Ltd.

This is an Open Access article distributed under the terms of the Creative Commons Attribution License (http://creativecommons.org/licenses/by/2.0), which permits unrestricted use, distribution, and reproduction in any medium, provided the original work is properly cited.

\begin{abstract}
Objective: Metformin has had a 'black box' contraindication in diabetic patients with heart failure (HF), but many believe it to be the treatment of choice in this setting. Therefore, we attempted to conduct a pilot study to evaluate the feasibility of undertaking a large randomized controlled trial with clinical endpoints.
\end{abstract}

Study Design: The pilot study was a randomized double blinded placebo controlled trial. Patients with HF and type 2 diabetes were screened in hospitals and HF clinics in Edmonton, Alberta, Canada (population I million). Major exclusion criteria included the current use of insulin or high dose metformin, decreased renal function, or a glycosylated hemoglobin $<7 \%$. Patients were to be randomized to $1500 \mathrm{mg}$ of metformin daily or matching placebo and followed for 6 months for a variety of functional outcomes, as well as clinical events.

Results: Fifty-eight patients were screened over a six month period and all were excluded. Because of futility with respect to enrollment, the pilot study was abandoned. The mean age of screened patients was 77 (SD 9) years and 57\% were male. The main reasons for exclusion were: use of insulin therapy $(n=23 ; 40 \%)$, glycosylated hemoglobin $<7 \%(n=17 ; 29 \%)$ and current use of high dose metformin $(n=12 ; 21 \%)$. Overall, contraindicated metformin therapy was the most commonly prescribed oral antihyperglycemic agent $(n=27 ; 51 \%)$. On average, patients were receiving I,706 mg (SD $488 \mathrm{mg}$ ) of metformin daily and 12 (44\%) used only metformin.

Conclusion: Despite uncertainty in the scientific literature, there does not appear to be clinical uncertainty with regards to the safety or effectiveness of metformin in HF making a definitive randomized trial virtually impossible.

Trial registration: ClinicalTrials.gov Identifier: NCT003259I0 


\section{Background}

Metformin has been approved for use in the treatment of type 2 diabetes mellitus for nearly 3 decades in Europe and Canada and for a decade in the United States (US). Numerous studies have shown metformin to be highly effective and safe in the treatment of type 2 diabetes [1-3]. Metformin is the only antidiabetic agent that has been shown to reduce mortality in patients newly diagnosed with type 2 diabetes and the only antidiabetic agent not shown to be associated with increased morbidity and mortality in patients with cardiac disease, including heart failure [2-5].

Despite this, product labeling for metformin in Canada, the US, and the EU state that it is contraindicated in most patients with heart failure, although recent changes have been made in the US [6-8]. Diabetes is a common comorbidity in patients with heart failure and portends a particularly poor prognosis[9,10]. As such, significant proportion of patients with diabetes may be potentially denied a beneficial treatment. It is thus not surprising that there has been a vigorous debate in the literature about whether or not metformin should be used in patients with heart failure and type 2 diabetes[4,7,11-24].

Indeed, a recent systematic review and meta-analysis suggests that in patients with comorbid heart failure and diabetes, metformin is the only agent which has not been associated with harm[25]. Importantly, the current evidence supporting metformin's use in heart failure is based on two population-based epidemiologic studies and both recommended confirmation of their findings in randomized trials [4,17]. Given the robust debate in the literature about the role of metformin in heart failure, this appeared to be a question that needed to be resolved with a randomized controlled trial[26].

We designed and implemented a pilot study, PHANTOM

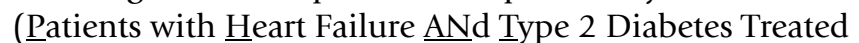
with Placebo Or Metformin), to evaluate the feasibility of a large randomized controlled trial of metformin in patients with heart failure and type 2 diabetes (ClinicalTrials.gov Identifier: NCT00325910). This paper describes our experiences in the implementation of the PHANTOM Pilot study and its implications for other clinical trials.

\section{Methods}

\section{Study Design}

The PHANTOM pilot study was a multi-centre, prospective randomized blinded placebo controlled trial designed to examine functionality, morbidity, and mortality outcomes in patients with heart failure and diabetes mellitus who are treated with metformin therapy over a 6 month period. Two hospitals, the University of Alberta Hospital and the Misericordia Hospital, and one outpa- tient specialized heart failure clinic in Edmonton, Alberta, Canada (population 1 million) participated in the study[27]. The University of Alberta Hospital is an 800bed tertiary university-based teaching hospital and has been a recruitment site for many major cardiovascular trials including the Digitalis Investigation Group (DIG) Trial, the Heart Outcomes Prevention Evaluation (HOPE) Study, the Studies of Left Ventricular Dysfunction (SOLVD), the Global Utilization of Streptokinase and Tissue Plasminogen Activator for Occluded Coronary Arteries (GUSTO) trials. The Misericordia Hospital is a 500-bed community hospital also involved in several large randomized trials in acute coronary syndromes and heart failure. The study protocol was reviewed and approved by the Research Ethics Board of all participating sites.

\section{Eligibility}

We screened consecutive patients older than 18 years, admitted to the hospital or emergency room or registered patients of the local heart failure clinics. Inclusion criteria were: physician diagnoses of symptomatic heart failure (NYHA class II, III, IV) and type 2 diabetes (i.e., a previous physician diagnosis or actively receiving oral antidiabetic agents or a new diagnosis of type 2 diabetes, defined as a fasting blood glucose $\geq 7.0 \mathrm{mmol} / \mathrm{L}$ or random blood glucose $\geq 11.1 \mathrm{mmol} / \mathrm{L}$, and accompanied by acute metabolic decompensation or 2 hour plasma glucose in a 75 gram oral glucose tolerance test $\geq 11.1 \mathrm{mmol} / \mathrm{L}$ )[28]. We excluded patients if they were receiving greater than 1500 mg of metformin daily, were unwilling to change their antidiabetic regimens, were receiving insulin therapy, had a serum creatinine $\geq 180 \mu \mathrm{mol} / \mathrm{L}$, had an $\mathrm{A} 1 \mathrm{c}<7.0 \%$, were unable to communicate because of language barriers, had dementia or mental illness, were unwilling to complete self-monitoring of serum blood sugars during the trial period, were participating in another heart failure or diabetes clinical trial involving medications, or had significant comorbidities or a terminal illness precluding them from following the trial protocol over the 6 month followup period.

\section{Screening}

Potential patients were identified through referrals of hospitalized or heart failure clinic patients. After identification, a two-stage screening process began. In stage 1, potentially eligible individuals were screened for noninvasive inclusion/exclusion criteria (i.e., all exclusion criteria except A1c and serum creatinine). In stage 2, patients who were not excluded after stage 1 were approached for consent to a blood sample to determine A1c and serum creatinine eligibility (if not previously completed as part of their clinic or hospital medical care). Eligible patients meeting all inclusion and exclusion criteria and consenting to the trial continued with the study protocol. 


\section{Randomization and study procedures}

Consenting patients were to be randomized to either metformin or matching placebo tablets in a 1:1 ratio. Randomization was planned through a secure website provided by the project office (Epidemiology Coordinating and Research (EPICORE) Centre, University of Alberta).

Patients were to be assessed at baseline and six months later, with monthly telephone contact to assess response to the study medication and ascertain clinical outcomes. Follow-up visits and blood testing (A1c and serum creatinine) were planned for 3 and 6 month visits. We planned a dosage titration protocol where patients would be instructed to slowly titrate their study medication to a maximum dose of $1500 \mathrm{mg}$ per day over a 3 week period based on a published titration protocol[1].

\section{Study Endpoints}

The primary outcome was a composite endpoint of allcause mortality or all-cause hospitalization. As secondary endpoints, comparisons of mean change in A1c, six minute walk distance, and mean change in health-related quality of life (i.e., RAND-12, EQ-5D, and Kansas City Cardiomyopathy Questionnaire) scores from baseline to the 6 month follow-up visit were also planned. In addition, we established criteria for monitoring safety of metformin, to identify patients developing lactic acidosis requiring urgent medical attention, as defined as an emergency room visit or hospitalization.

\section{Sample Size Considerations}

We anticipated the full study would require a sample size of 1000 patients with heart failure and diabetes to detect an absolute difference in event rates of at least $10 \%$ based on an incidence rate of 50\%[29] in our primary outcome per year with a two-tailed alpha $=0.05$ and beta $=0.10$. The goal of the pilot study was to enroll 100 patients.

\section{Results}

Recruitment for the study began May 1, 2006. As of October $15^{\text {th }}, 2006$, fifty-eight consecutive patients with diabetes and heart failure were screened through the outpatient ambulatory heart failure clinic $(\mathrm{n}=8,14 \%)$ and in-patient cardiology and general medical wards $(n=50,86 \%)$ with no patients meeting eligibility criteria. Using a conservative estimate of 1 patient enrolled for every 10 patients screened, our data suggests that the likelihood that a significant number of potentially eligible patients were missed during screening would be less than 5\%. Indeed, review of the Regional Diabetes Program electronic databases, which at the time contained approximately 500 individuals with type 2 diabetes and heart failure, suggests very few patients $(<1 \%)$ would have been potentially eligible for the trial. This poor availability of suitable patients led the Steering Committee to recommend that the study be abandoned.

The characteristics of the individuals screened for the pilot study are shown in Table 1 . Of note, 5 patients refused to have their screening data collected and are therefore not included in our results. Of the patients admitted to hospital $(\mathrm{n}=45,85 \%)$, heart failure $(\mathrm{n}=22,49 \%)$ was the most common admitting diagnosis. Acute coronary syndromes $(\mathrm{n}=7,16 \%)$ and diabetes $(\mathrm{n}=4(9 \%)$ were the next most common reasons for admission. The median length of stay in hospital was 12 days (interquartile range 9 to 36 ).

Overall, the patients screened represented a typical population of patients with heart failure with $57 \%$ males and an average age of 77 (SD 9) years. At the time of screening, $51(96 \%)$ patients were receiving an angiotensin converting enzyme (ACE) inhibitor or angiotension receptor blockers (ARB) (Table 1). Approximately two-thirds of patients were also receiving beta-blockers, antiplatelet and lipid-lowering therapies with 27 (51\%) patients receiving all three therapies.

The use of insulin $(\mathrm{n}=23,43 \%)$ was the most common reason for trial exclusion (Figure 1 ). Of the patients receiving insulin therapy, $11(48 \%)$ had additional exclusion criteria. Overall, 11 (48\%) patients received insulin in combination with oral antidiabetic agents. The second most common reason for exclusion from the trial was an A1c value less than $7 \%$. Of the patients who had an A1c available ( $\mathrm{n}=35,65 \%), 17$ (49\%) patients were excluded with an A1c less than 7\% reported in their medical records (Figure 1). The mean A1c was 7.3\% (SD 2) (Table 1). This may misrepresent the true A1c values, however, as not all patients had an A1c measured due to the two stage screening protocol.

Despite being 'absolutely' contraindicated in this population during our period of study, metformin was the most commonly prescribed oral antidiabetic agent with 27 (51\%) patients receiving it at the time of screening (Table $1)$. In comparison, few patients were receiving therapy with sulfonylureas, thiazolidinediones, meglitinides or alpha glucosidase inhibitors (Table 1). Although the duration of therapy with metformin in these patients was not ascertained, 4 subjects with heart failure were newly initiated on metformin during their hospitalization. Of the patients receiving metformin, 12 (44\%) were receiving greater than $1500 \mathrm{mg}$ per day and were therefore excluded from our study (Figure 1). On average, patients were receiving 1,706 $\mathrm{mg}$ per day (SD 488) with $2000 \mathrm{mg}$ per day as the most common daily dose regimen. Twelve (44\%) patients used metformin as monotherapy, 9 (33\%) in combination with other oral agents and $6(22 \%)$ in combination with insulin alone. Metformin was also 
Table I: Clinical characteristics of screened patients

\begin{tabular}{|c|c|c|c|c|}
\hline Characteristic* & $\begin{array}{l}\text { Overall Group } \\
\qquad(n=53)^{*}\end{array}$ & $\begin{array}{c}\text { Non-Metformin User } \\
(n=26)\end{array}$ & $\begin{array}{l}\text { Metformin User } \\
(n=27)\end{array}$ & P-value $\neq$ \\
\hline & & \multicolumn{2}{|c|}{ No. (\%) or Mean \pm SD } & \\
\hline Age - yrs & $76.5 \pm 8.6$ & $78.2 \pm 8.5$ & $74.9 \pm 8.7$ & 0.17 \\
\hline Sex - male & $30(57)$ & $16(62)$ & $14(52)$ & 0.48 \\
\hline Weight $(\mathrm{kg})$ & $82 \pm 25$ & $80 \pm 22$ & $84 \pm 28$ & 0.74 \\
\hline Serum Creatinine $(\mu \mathrm{mol} / \mathrm{L})$ & $135 \pm 64$ & $147 \pm 75$ & $123 \pm 49$ & 0.17 \\
\hline Creatinine Clearance ( $\mathrm{ml} / \mathrm{min})$ & $49 \pm 23$ & $45 \pm 18$ & $53 \pm 26$ & 0.19 \\
\hline $\operatorname{Alc}(\%)^{\dagger}$ & $7.3 \pm 0.02$ & $6.8 \pm 1.2$ & $7.7 \pm 2.6$ & 0.22 \\
\hline \multicolumn{5}{|l|}{ Heart Failure Medications } \\
\hline Beta-Blockers & $38(72)$ & $18(69)$ & $20(74)$ & 0.70 \\
\hline ACE Inhibitors or ARBs & $51(96)$ & $26(100)$ & $25(93)$ & 0.49 \\
\hline Calcium Channel Blockers & $18(34)$ & $8(31)$ & $10(37)$ & 0.63 \\
\hline Antiplatelet Agents & $44(83)$ & $21(8 I)$ & $23(85)$ & 0.73 \\
\hline Digoxin & $9(17)$ & $4(15)$ & $5(19)$ & 1.0 \\
\hline Spironolactone & $12(23)$ & $5(19)$ & $7(26)$ & 0.56 \\
\hline Lipid Therapy & $4 \mid(77)$ & $19(73)$ & $22(82)$ & 0.47 \\
\hline Nitrates & $10(19)$ & $4(15)$ & $6(22)$ & 0.73 \\
\hline \multicolumn{5}{|l|}{ Diabetes Medications } \\
\hline Insulin & $23(43)$ & $15(58)$ & $8(30)$ & 0.039 \\
\hline Sulfonylureas & $8(15)$ & $3(12)$ & $5(19)$ & 0.70 \\
\hline Thiazolidinediones & $4(8)$ & I (4) & $3(I I)$ & 0.61 \\
\hline Meglitinides & $2(4)$ & I (4) & I (4) & 1.00 \\
\hline
\end{tabular}

* - five patients refused to have data included

$\dagger-34$ people had Alc assessed in previous 3 months; 15 people in non-metformin user and 19 people in metformin user groups

$\ddagger-$ for comparison between non-metformin and metformin group

more commonly prescribed in combination with insulin than other oral agents. Of the 23 patients receiving insulin therapy, 8 (35\%) were also prescribed metformin. We saw no significant differences between patients receiving metformin and non-metformin regimens in terms of clinical or demographic characteristics (Table 1).

\section{Discussion}

A guiding principle for the conduct of a randomized controlled trial is that of equipoise, or perhaps more appropriately 'uncertainty' as to whether the therapy under study works[26]. Although metformin has been demonstrated to improve outcomes, its use in people with heart failure and type 2 diabetes is still a contentious issue. Clinicians and researchers have argued both sides of the issue providing strong evidence for the criterion of uncertainty[4,7,11-24]. Results of our pilot study would suggest, however, that there may be discordance between the scientific community and practicing clinicians.

Over $50 \%$ of patients with diabetes and heart failure in our pilot study were receiving metformin, either alone or in combination with other antidiabetic agents, suggesting there is no uncertainty in the eyes of clinicians. Although this may be surprising, one must consider that metformin therapy is one of the most commonly prescribed antidiabetic agents and has a long history of use in Canada.
Indeed, a recent population based study using Canadian data suggested that two-thirds of all patients with type 2 diabetes treated with antidiabetic medications receive metformin therapy, either alone or in combination with other agents[30]. Furthermore, observational data in Canada, Europe, and the US have shown that 20 to $25 \%$ of patients receiving metformin therapy also have comorbid heart failure $[4,11,17,20,23,31,32]$ and US data has indicated that the use of metformin has increased by over $50 \%$ in patients with heart failure in recent years[12]. In our pilot study, half of all subjects were actively receiving metformin therapy with the majority of people receiving relatively high doses of metformin therapy (i.e., >1500 mg/ day). Given the accumulated research, including our pilot data, it would seem there is little uncertainty at the clinician level regarding the use of metformin in patients with heart failure.

Should there be uncertainty with regards to the use of metformin in patients with heart failure? Perhaps not, considering the evidence base for the efficacy of metformin in type 2 diabetes. Indeed, numerous observational and randomized controlled studies have clearly shown metformin to be highly efficacious for patients with type 2 diabetes[1-4,17]. Moreover, epidemiological evidence has suggested that metformin may be associated with improved outcomes in patients with heart fail- 


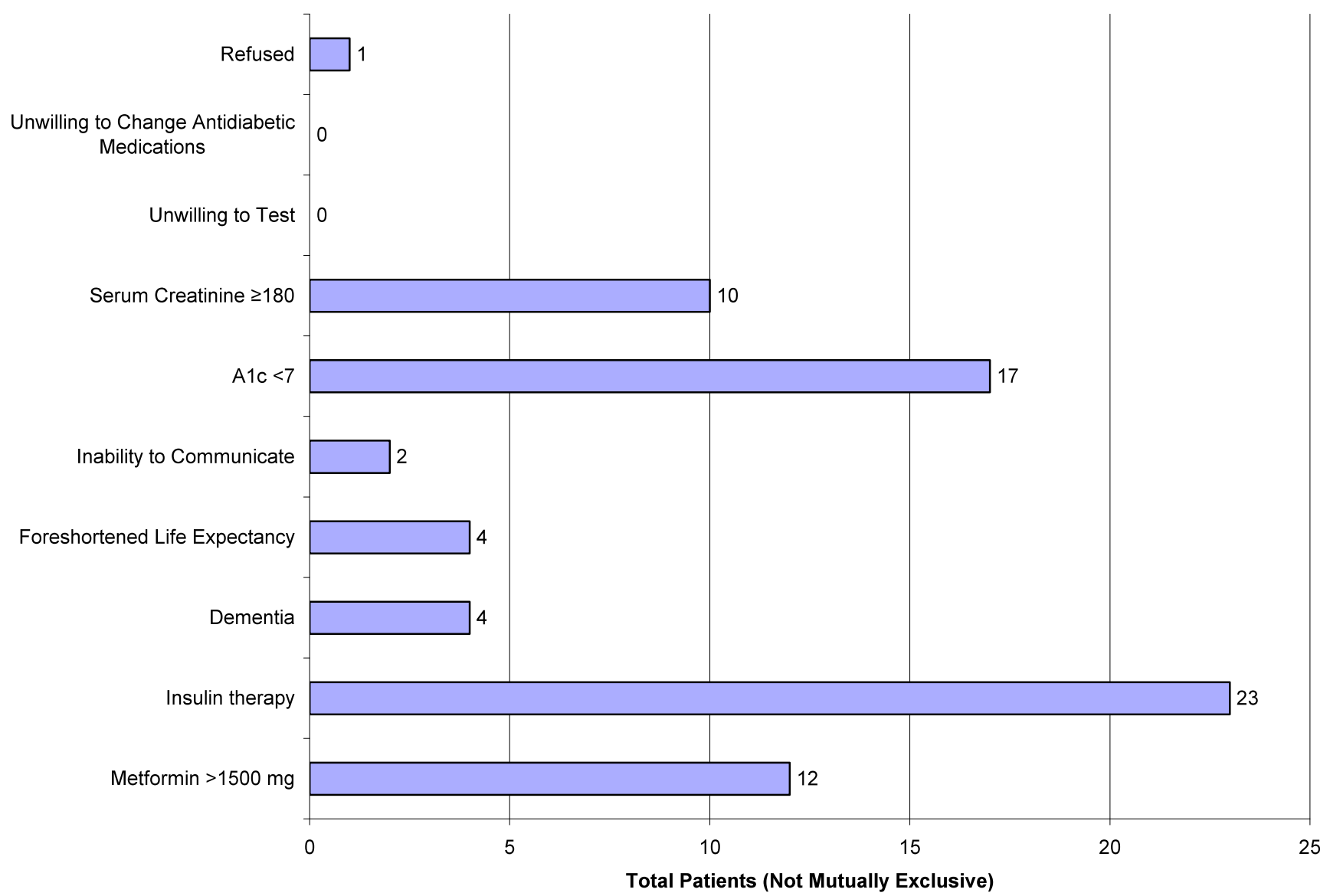

Figure I

Reason for study exclusion.

ure $[4,17,25]$. The potential scientific uncertainty with using metformin in patients with heart failure seems to be focused on the risks rather than the possible benefits. One should note, however that although there are two large meta-analyses and a case series indicating that the risk of lactic acidosis with metformin is an extremely rare event occurring at the same rate as other antidiabetic agents, uncertainty around its safety suggested that a randomized controlled trial was warranted. This uncertainty, however, seems to be waning.

Since the implementation of the pilot study, several fundamental changes have occurred surrounding the use of metformin in both Canada and the United States. In 2007, the United States Food and Drug Administration removed the heart failure contraindication from the packaging label for metformin therapy (Glucophage ${ }^{\circledast}$ and Glucophage $\left.\mathrm{XR}^{\circledR}\right)$; however, a 'black-box' warning still exists for the use of metformin in this population suggesting caution if it is used at all. Similar labeling changes have not yet occurred in Canada, although the 2008 Canadian Dia- betes Association clinical practice guidelines have indicated that metformin should be considered as first-line therapy in patients with heart failure (Grade C, Level 3 [observational evidence])[33].

Our experience should be viewed in light of several other considerations. The inability to enroll patients into the pilot study may have been influenced by numerous factors including the patient-clinician relationship and the perceived importance of the trial[34]. It is possible, for example, that admitting the potential uncertainty of using metformin in heart failure by the clinician may be perceived as damaging to the patient-clinician relationship; thereby becoming a barrier to patient enrollment $[35,36]$. Although all clinicians directly involved in our study were supportive, those outside of the study may not have believed the research question was of interest or importance[37]. It is also possible that despite the contraindication at the time, individual clinicians prescribing for these patients felt that the benefits outweighed any potential risks, and may have felt uneasy with the potential with- 
drawal of metformin therapy. If this is indeed the case, even if a successful randomized control trial was conducted, one must ask "will it substantially alter prescribing patterns of the front line clinician?" Numerous examples exist in the literature where randomized controlled trials have changed the collective thinking of the scientific community but have failed to make significant impacts on the prescribing patterns of individual clinicians[38].

In addition, as with any clinical trial, the inclusion and exclusion criteria clearly affected potential enrollment. We feel, however, few modifications could be made to our already liberal inclusion criteria, requiring only a physician diagnosis of heart failure and type 2 diabetes. Previous metformin use was not an exclusion criteria but patients receiving high dose metformin therapy $(>1500$ $\mathrm{mg}$ /day) were excluded as it was considered unethical to potentially randomize patients to placebo for a medication previously deemed necessary by a physician. Similarly, patients with adequate control of their diabetes (i.e., A1c $<7 \%$ ) were also excluded as it was deemed potentially unsafe to initiate another antidiabetic therapy. With respect to renal function, the current product monograph recommends that metformin be avoided in patients with a creatinine clearance $<60 \mathrm{~mL} / \mathrm{min}[6]$. In our study, the criteria was considerably more liberal, allowing patients with renal function as low as $20-30 \mathrm{~mL} / \mathrm{min}$. Of note, the use of metformin in the setting of chronic kidney disease with glomerular filtration rates less than $60 \mathrm{ml} / \mathrm{min}$ is also a major contraindication where labeling remains an issue.

Lastly, patients using insulin therapy were excluded. Previous research has suggested that insulin therapy may be associated with an increased risk of heart failure[10,39] and also an increased risk of mortality in people with diabetes and heart failure $[5,40,41]$. We therefore felt it was important to exclude this treatment to focus on the effects of metformin. Even if we had not excluded insulin users, $48 \%$ of these patients would not have been eligible due to other exclusions. As a result, changes in the inclusion and exclusion criteria would likely have not significantly altered our study outcome.

\section{Conclusion}

Our pilot data, coupled with the recent legal and clinical guideline endorsement for the use of metformin in heart failure patients, suggest that any future large randomized controlled trials with metformin in patients with heart failure and diabetes will be an arduous undertaking. Given the already frequent and increasing clinical experience of using metformin in patients with heart failure, a trial design which limits the use of metformin therapy may have difficulties in gaining clinician commitment as clinical uncertainty does not appear to exist[26]. If safety is still the true concern, it is well known that randomized controlled trials are, by design, ill suited to address the issue of safety, especially when rare events are concerned $[42,43]$. As a result, a large, well designed, phase 4, prospective evaluation of metformin use in patients with heart failure may provide the best evidence[42,43].

\section{Competing interests}

The authors declare that they have no competing interests.

\section{Authors' contributions}

All authors were involved in the conception and design and acquisition of data. DTE analyzed the data and drafted the first manuscript. All authors were involved in the interpretation of the data and revised it critically for important intellectual content. All authors read and approved the final manuscript.

The funding sources had no role in the design and conduct of the study; the collection, analysis, interpretation of the data, or in the decision to submit the manuscript for publication.

\section{Acknowledgements}

The authors wish to thank Bonnie Woloschuk, RN for the significant time and energy committed to the project. The authors also thank the Epidemiology Coordinating and Research (EPICORE) Centre http://www.epi core.ualberta.ca of the University of Alberta for providing services related to trial coordination and data management. Last, the authors wish to thank the University Hospital Foundation (UHF) for the grant to conduct the pilot study.

Role of Funding: The study was funded by an unrestricted grant from University Hospital Foundation. Dr. Eurich held a Full-time Studentship in Health Research with the Canadian Institutes for Health Research (CIHR). Dr Eurich is a Population Health Investigator, and Drs. Johnson, Majumdar and McAlister are Health Scholars with the Alberta Heritage Foundation for Medical Research (AHFMR). Dr. McAlister and Dr. Tsuyuki hold the Merck Frosst/Aventis Chair in Patient Health Management. Dr. Johnson holds a Canada Research Chair in Diabetes Health Outcomes. Dr. Johnson is Chair of a New Emerging Team (NET) grant to the Alliance for Canadian Health Outcomes Research in Diabetes (ACHORD).

The ACHORD NET grant is sponsored by the Canadian Diabetes Association, the Heart and Stroke Foundation of Canada, The Kidney Foundation of Canada, the CIHR - Institute of Nutrition, Metabolism and Diabetes and the CIHR - Institute of Circulatory and Respiratory Health.

\section{References}

I. DeFronzo RA, Goodman AM: Efficacy of metformin in patients with non-insulin-dependent diabetes mellitus. The Multicenter Metformin Study Group. N Engl J Med 1995, 333:54I-549.

2. Johnson JA, Majumdar SR, Simpson SH, Toth EL: Decreased mortality associated with metformin use compared to sulfonylurea monotherapy in type 2 diabetes mellitus. Diabetes Care 2002, 25:2244-2248.

3. UK Prospective Diabetes Study group: Effect of intensive bloodglucose control with metformin on complications in overweight patients with type 2 diabetes (UKPDS 34). Lancet 1998, 352:854-865. 
4. Eurich DT, Majumdar SR, McAlister FA, Tsuyuki RT, Johnson JA Improved Clinical Outcomes Associated With Metformin in Patients With Diabetes and Heart Failure. Diabetes Care 2005 28:2345-235I.

5. Smooke S, Horwich TB, Fonarow GC: Insulin-treated diabetes is associated with a marked increase in mortality in patients with advanced heart failure. Am Heart J 2005, 149:168-174.

6. Canadian Pharmaceutical Association: Compendium of pharmaceuticals and specialties (Canada) 2004.

7. Inzucchi SE: Metformin and heart failure: innocent until proven guilty. Diabetes Care 2005, 28:2585-2587.

8. Inzucchi SE, Masoudi FA, McGuire DK: Metformin in heart failure. Diabetes Care 2007, 30:el 29.

9. Nichols GA, Gullion CM, Koro CE, Ephross SA, Brown JB: The incidence of congestive heart failure in type 2 diabetes: an update. Diabetes Care 2004, 27:1879-1884.

10. Kannel WB, Hjortland M, Castelli WP: Role of diabetes in congestive heart failure: the Framingham study. Am J Cardiol 1974 34:29-34.

II. Holstein A, Nahrwold D, Hinze S, Egberts EH: Contra-indications to metformin therapy are largely disregarded. Diabet Med 1999, 16:692-696

12. Masoudi FA, Wang Y, Inzucchi SE, Setaro JF, Havranek EP, Foody JM, Krumholz HM: Metformin and thiazolidinedione use in Medicare patients with heart failure. JAMA 2003, 290:8I-85.

13. Misbin RI: The phantom of lactic acidosis due to metformin in patients with diabetes. Diabetes Care 2004, 27:179|-1793.

14. Stang M, Wysowski DK, Butler-Jones D: Incidence of lactic acidosis in metformin users. Diabetes Care 1999, 22:925-927.

15. Fantus IG: Metformin's contraindications: needed for now. Canadian Medical Association Journal 2005, 173:505-507.

16. Salpeter SR, Greyber E, Pasternak GA, Salpeter EE: Risk of fatal and nonfatal lactic acidosis with metformin use in type 2 diabetes mellitus: systematic review and meta-analysis. Arch Intern Med 2003, 163:2594-2602

17. Masoudi FA, Inzucchi SE, Wang Y, Havranek EP, Foody JM, Krumholz HM: Thiazolidinediones, metformin, and outcomes in older patients with diabetes and heart failure: an observational study. Circulation 2005, I I I:583-590.

18. Horlen C, Malone R, Bryant B, Dennis B, Carey T, Pignone M, Rothman R: Frequency of inappropriate metformin prescriptions. JAMA 2002, 287:2504-2505.

19. McCormack J, Johns K, Tildesley H: Metformin's contraindications should be contraindicated. CMAJ 2005, 173:502-504.

20. Emslie-Smith AM, Boyle DI, Evans JM, Sullivan F, Morris AD: Contraindications to metformin therapy in patients with Type 2 diabetes - a population-based study of adherence to prescribing guidelines. Diabet Med 200I, 18:483-488.

21. Howlett HC, Bailey CJ: A risk-benefit assessment of metformin in type 2 diabetes mellitus. Drug Saf 1999, 20:489-503.

22. Levenson D: Patients with both diabetes and heart failure often treated with medications government considers unsafe. Report on Medical Guidelines \& Outcomes Research 2003 , I 4: I-7.

23. Rachmani R: Metformin in patients with type 2 diabetes mellitus: Reconsideration of traditional contraindications. European Journal of Internal Medicine 2002, 13:428-433.

24. Sulkin TV, Bosman D, Krentz AJ: Contraindications to metformin therapy in patients with NIDDM. Diabetes Care 1997, 20:925-928.

25. Eurich DT, McAlister FA, Blackburn DF, Majumdar SR, Tsuyuki RT, Varney J, Johnson JA: Benefits and harms of antidiabetic agents in patients with diabetes and heart failure: systematic review. $B M$ / 2007, 335:497.

26. Sackett $D L$ : Why randomized controlled trials fail but needn't: I. Failure to gain "coal-face" commitment and to use the uncertainty principle. CMA/ 2000, 162:|3||-|3|4.

27. Majumdar SR, Rowe BH, Folk D, Johnson JA, Holroyd BH, Morrish DW, Maksymowych WP, Steiner IP, Harley $\mathrm{CH}$, Wizba BJ, Hanley DA, Blitz A, Russell AS: A controlled trial to increase detection and treatment of osteoporosis in older patients with a wrist fracture. Ann Intern Med 2004, 14 I:366-373.

28. Canadian Diabetes Association Clinical Practice Guidelines Expert Committee: Canadian Diabetes Association 2003 Clinical Practice Guidelines for the Prevention and Management of Diabetes in Canada. Can J Diabetes 2003, 27:sI-sI52.
29. Tsuyuki RT, Fradette M, Johnson JA, Bungard TJ, Eurich DT, Ashton T, Gordon W, Ikuta R, Komder J, Mackav E, Manyari D, O"Reilly K, Semchuk W: A multicenter disease management program for hospitalized patients with heart failure. J Card Fail 2004, 10:473-480

30. Johnson JA, Pohar SL, Secnik K, Yurgin N, Hirji Z: Utilization of diabetes medication and cost of testing supplies in Saskatchewan, 200 I. BMC Health Serv Res 2006, 6:159.

31. Besner HK, Feemster AA, Bongiorno RA: Evaluation of metformin use in hospitalized patients. Ashp Midyear Clinical Meeting 2004, 39:243E.

32. Khandwala HM: The prevalence of contraindications to the use of metformin. Can J Diabetes 2004, 28:380-384.

33. Canadian Diabetes Association Clinical Practice Guidelines Expert Committe: Canadian Diabetes Association 2008 clincal practice guidelines for the prevention and management of diabetes in Canada. Can J Diabetes 2008, 32(suppI I):SI-S20I.

34. Prescott RJ, Counsell CE, Gillespie WJ, Grant AM, Russell IT, Kiauka S, Colthart IR, Ross S, Shepherd SM, Russell D: Factors that limit the quality, number and progress of randomised controlled trials. Health Technol Assess 1999, 3:1-143.

35. Taylor KM, Margolese RG, Soskolne CL: Physicians' reasons for not entering eligible patients in a randomized clinical trial of surgery for breast cancer. N Engl J Med I984, 3 I 0: |363-I367.

36. Benson AB III, Pregler JP, Bean JA, Rademaker AW, Eshler B, Anderson $\mathrm{K}$ : Oncologists' reluctance to accrue patients onto clinical trials: an Illinois Cancer Center study. J Clin Oncol I99I, 9:2067-2075

37. Tognoni G, Alli C, Avanzini F, Bettelli G, Colombo F, Corso R, Marchiolo $R$, Zussino A: Randomised clinical trials in general practice: lessons from a failure. $B M]$ | 99|, 303:969-97|.

38. Majumdar SR, McAlister FA, Furberg CD: From knowledge to practice in chronic cardiovascular disease: a long and winding road. I Am Coll Cardiol 2004, 43: I738-1742.

39. Nichols GA, Hillier TA, Erbey JR, Brown JB: Congestive heart failure in type 2 diabetes: prevalence, incidence, and risk factors. Diabetes Care 200I, 24:1614-1619.

40. Pocock SJ, Wang D, Pfeffer MA, Yusuf S, McMurray JJ, Swedberg KB, Ostergren J, Michelson EL, Pieper KS, Granger CB: Predictors of mortality and morbidity in patients with chronic heart failure. Eur Heart J 2006, 27:65-75.

4I. Murcia AM, Hennekens CH, Lamas GA, Jimenez-Navarro M, Rouleau JL, Flaker GC, Goldman S, Skali H, Braunwald E, Pfeffer MA: Impact of diabetes on mortality in patients with myocardial infarction and left ventricular dysfunction. Archives of Internal Medicine 2004, 164:2273-2279.

42. Laupacis A, Mamdani M: Observational studies of treatment effectiveness: some cautions. Ann Intern Med 2004, 140:923-924.

43. D'Agostino RB Jr, D'Agostino RB Sr: Estimating treatment effects using observational data. JAMA 2007, 297:3|4-3|6.

Publish with Bio Med Central and every scientist can read your work free of charge

"BioMed Central will be the most significant development for disseminating the results of biomedical research in our lifetime. "

Sir Paul Nurse, Cancer Research UK

Your research papers will be:

- available free of charge to the entire biomedical community

- peer reviewed and published immediately upon acceptance

- cited in PubMed and archived on PubMed Central

- yours - you keep the copyright 